\title{
A guide for proper utilisation of stable isotope reference materials.
}

\author{
MEIER-AUGENSTEIN, W. and SCHIMMELMANN, A.
}

2019

This is an Accepted Manuscript of an article published by Taylor \& Francis in Isotopes in environmental and health studies on 08-11-2018, available online:

http://www.tandfonline.com/10.1080/10256016.2018.1538137. 


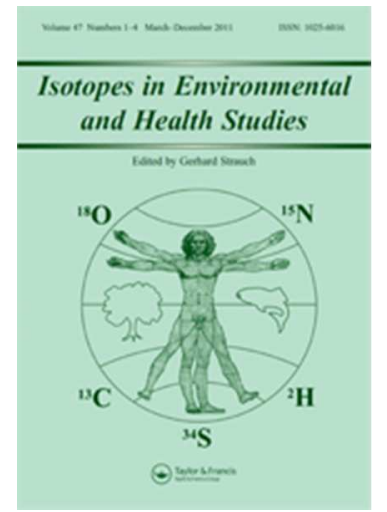

\section{A guide for proper utilization of Stable Isotope Reference Materials}

\begin{tabular}{|r|l|}
\hline Journal: & Isotopes in Environmental \& Health Studies \\
\hline Manuscript ID & Draft \\
\hline Manuscript Type: & Original Article \\
\hline Date Submitted by the Author: & $\mathrm{n} / \mathrm{a}$ \\
\hline Complete List of Authors: & $\begin{array}{l}\text { Meier-Augenstein, Wolfram; Robert Gordon University, School of Pharmacy } \\
\text { \& Life Science } \\
\text { Schimmelmann, Arndt; University of Indiana, Department of Geological } \\
\text { Sciences }\end{array}$ \\
\hline Keywords: & $\begin{array}{l}\text { isotope abundance, Isotope measurements, methods and equipment, } \\
\text { reference material, scale anchor, stretch factor, scale compression, scale } \\
\text { normalisation, delta scale reference point }\end{array}$ \\
\hline
\end{tabular}

\section{SCHOLARONE \\ Manuscripts}




\title{
A guide for proper utilization of Stable Isotope Reference Materials
}

\author{
Wolfram Meier-Augenstein ${ }^{1}$ and Arndt Schimmelmann ${ }^{2}$
}

${ }^{1}$ School of Pharmacy and Life Sciences, Robert Gordon University, The Sir Ian Wood

Building, Garthdee Road, Aberdeen,AB10 7GJ,UK;w.meier-augenstein@rgu.ac.uk

${ }^{2}$ Department of Earth and Atmospheric Sciences, Indiana University, 1001 East 10th Street, Bloomington, Indiana 47405-1405, United States; aschimme@indiana.edu 


\title{
A guide for proper utilization of Stable Isotope Reference Materials
}

\begin{abstract}
Many scientific publications about stable isotope ratios suffer from flawed practices regarding calibration and normalisation of raw $\delta$ values in conjunction with prescribed $\delta$ values of reference materials. Violations of the Identical Treatment principle with regards to samples and standards (i.e. reference materials) and lack of adherence to SImandated and IUPAC-recommended nomenclature exacerbate the widespread problem of lackadaisical analytical practice and reporting. Science is supposed to strive for exactness, whereas ambiguity and jargon confound interdisciplinary communication. This contribution aims to expose typical misconceptions and avoidable errors and offers guidance toward reproducible generation of isotope data, isotopic scale normalisation, and proper data reporting. We offer a comprehensive overview of sources of light stable isotope reference materials to best match sample matrices encountered by stable isotope practitioners with chemically similar reference materials.
\end{abstract}

Keywords: calibration; isotope abundance; isotope abundance calibration; reference material; scale anchor; scale compression; scale normalisation; stable isotope; stretch factor

\section{Introduction}

The exponential growth of global scientific output fosters compartmentalisation into sub-disciplines with specialized jargons and cryptic conventions. Practitioners of stable isotope analyses are spread over many poorly connected scientific fields from archaeology over ecology and forensics to geochemistry to name but a few [1-5]. Fruitful interdisciplinary communication mandates that scientific results should be measured reproducibly and reported unambiguously based on internationally accepted scientific units and nomenclature [6, 7]. This contribution aims to provide a guide towards generating and reporting stable isotope data with quality assurance and transparency. Adherence to such principles will facilitate publication of results as well as interdisciplinary understanding. 
It is probably fair to say neither reviewers nor editors of scientific journals would accept and publish manuscripts reporting quantitative data based on mass spectrometric (MS) analysis if such data were not supported by a multi-point calibration. So, why should manuscripts reporting isotope abundance data based on isotope ratio mass spectrometric (IRMS) analysis be treated any differently? The answer of course is they should not. While failure to calibrate an analytical method to compensate for method and/or instrument inherent differences between measured and accepted (known to be true) values will present problems in any subject of natural or life sciences, this is of particular concern in subject areas impacting on public health and safety including consumer protection such as food authenticity (or food forensics), authenticity of pharmaceutical drugs or forensic science. Lack of traceability to internationally recognised scale anchors and lack of inter-laboratory comparability of such non-calibrated data undermines not just confidence in the data but confidence in the conclusions drawn. This would be particularly regrettable if such data were to be presented and refuted in court [8]. Yet, many an example of articles reporting such data can be found in journals dedicated to food authenticity or forensic science to this day.

This article therefore aims to dispel any misconceptions that may still exist concerning isotope abundance calibration or isotopic scale normalisation of measured stable isotope abundance data by explaining the concept of stable isotope reference materials and by illustrating how to use them and how not to.

\section{Why multi-point isotopic calibration is a must}

Having referred to multi-point calibration being a prerequisite for quantitative MS analysis, let us briefly explore the similarity or analogous principles between quantitative compound MS analysis and compound isotope abundance analysis by IRMS. In quantitative MS analysis calibration aims to determine the relation between compound amount or 
concentration and detector response. Even though the detector response of MS instruments is directly proportional to compound amount, performance variability of the different instrument components results in uncertainty levels of $>10 \%$ relative standard deviation (RSD), too poor for reliable quantification. Repeatedly carried out calibration series can therefore yield widely differing calibration curves even though individually each calibration curve can be all but perfectly linear (Figure 1a). To overcome this problem quantitative MS analysis relies on the use of internal standards (IS). Calibration curves are based on the analysis of varying concentrations of the target compound(s) to which always the same amount of internal standard(s) has been added. Calibration curves are constructed by plotting abundance ratios of quantifying ion compound over quantifying ion IS (Figure 1b). This approach is associated with uncertainty levels of $<1 \%$ RSD since any factors ultimately affecting detector response will affect target compound and IS measurement in the same way and by building the ratio will cancel each other out.

The situation we encounter when analysing compounds for the abundance of the heavier isotope of a given light element by IRMS is similar and yet somewhat different. One could say calibration in quantitative MS and IRMS are two different sides of the same coin. Isotope abundance analysis also aims to determine a quantitative answer, namely, the true amount of a given isotope present in a compound or material. However, for a number of reasons the analytical answer is not an absolute amount but a ratio of the heavier isotope abundance over the lighter isotope abundance of the sample (S) relative to the known isotope abundance ratio of a standard (STD).

$$
\delta^{h} E_{S / S T D}=\frac{R_{S}-R_{S T D}}{R_{S T D}}=\frac{R_{S}}{R_{S T D}}-1
$$

The result of this ratio of ratios calculation is the delta value $(\delta)$ of the heavier isotope $\mathrm{h}$ of a given element E (Equation 1). Numerical results of this equation are typically quite 
small, e.g. -0.02996 which is why for reasons of convenience they may be expressed as \%o values where -0.02996 is written as $-29.96 \times 10^{-3}$ or $-29.96 \%$. So, like quantitative MS analysis of compound abundance IRMS analysis of stable isotope abundance yields a quantitative answer yet with one subtle difference. Unlike quantitative MS analysis the result of IRMS analysis can be either a negative or a positive number because measurement results are expressed relative to an internationally agreed scale zero point. A negative number therefore indicates the stable isotope abundance in a given compound is less than that of the primary reference material defining the scale zero point. Conversely, a positive number indicates the stable isotope abundance in a given compound is higher than that of the primary reference material defining the scale zero point.

It is important to note, like \% values this is purely a mathematical convention but should not be confused with an SI unit of measurement (SI = Système International a.k.a. International System). Should one wish to avoid the \%o notation (and thus the \%o symbol) being confused with an SI unit, particularly in graphs and tables, one can present relative abundance data as $10^{3} \times \delta$ values [9, 10]. In line with the established practice to attribute SI supplementary units to values derived from ratios where units cancel each other (e.g. the Reynolds number [Re]) the term "urey" (symbol Ur) has been proposed so that $\delta$ values traditionally written as e.g. -29.96 \%o can be written as -29.96 mUr [6].

While in theory any compound could be used as standard as long as its isotope abundance with regards to ${ }^{\mathrm{h}} \mathrm{E}$ were known or defined, it is obvious that $\delta$ values thus obtained could not be compared between different laboratories unless all laboratories would use subsamples of the same standard material. However, would one standard suffice to quantify isotope abundance of a given element in a given compound or material? The answer is no of course. We know ${ }^{13} \mathrm{C}$ abundance in chemically identical compounds like sugars can differ widely depending by which photosynthetic pathway they were produced [11-13]. In other 
words, in analogy to the need in quantitative MS analysis for concentration or abundance calibration based on several but at least two standard preparations containing different amounts of the target compound there is a similar need in quantitative isotope abundance IRMS analysis for several but at least two standards of preferably identical chemical composition but of different isotope abundance (i.e. isotopic specific quantity). For this reason alone $\delta$ values obtained by comparative measurement to a single cylinder gas are neither calibrated nor scale normalized. It could of course be argued multi-point calibration should not be necessary considering we are measuring relative isotope abundance values. However, such an argument fails to take into account a phenomenon particular to IRMS analysis called scale compression $[14,15]$. Scale compression is essentially the sum of all mass discriminatory effects associated with sample gas transfer to the IRMS, sample gas admission into the ion source of the IRMS and possibly processes inside the ion source itself. The measurable consequence of scale compression is most noticeable and thus most detrimental to accuracy in ${ }^{2} \mathrm{H}$ abundance analysis as illustrated by the examples presented in Table 1. In that instance the difference between SLAP2's measured $\delta^{2} \mathrm{H}$ value and its scale

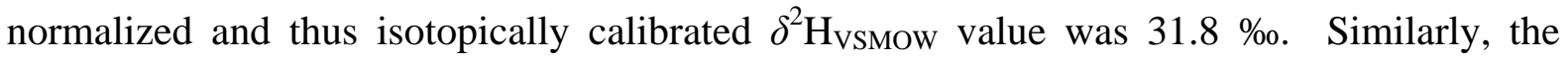
difference between the measured $\delta^{2} \mathrm{H}$ value of NBS 22 and its scale calibrated $\delta^{2} \mathrm{H}_{\mathrm{VSMOW}}$ value of $-117.0 \%$ (accepted $\delta^{2} \mathrm{H}_{\text {VSMOw }}$ value of $-117.2 \%$ [16]) was $8.5 \%$ o, representing a relative difference of $7.25 \%$ between measured and accepted ${ }^{2} \mathrm{H}$ abundance value. This example alone illustrates the importance of using reference materials when carrying out stable isotope abundance measurements. Equally, this example illustrates the importance of reporting which international reference materials have been used as scale anchors for the respective stable isotope scales and which accepted $\delta$ values have been employed [7]. There are numerous instances where well-established international reference materials like NBS 22 or IAEA-CH-7 have been repeatedly isotopically re-evaluated over time. 


\section{Why internationally accepted reference materials are important}

The inescapable conclusions from the foregoing are these. Internationally accepted reference materials (RMs) are required that satisfy two needs.

(I) Ensuring relative isotope abundance measurements can be calibrated to internationally agreed methodology so calibrated $\delta$ values can be compared between laboratories on a like-for-like basis.

(II) Ensuring relative isotope abundance measurements can be corrected for any scale distorting effects so calibrated delta values are anchored to internationally agreed isotope abundance scales as defined for a particular element.

In addition to delivering highly comparable data, reference materials meeting these two conditions will also put in place a good traceability system. There are other practical but equally important reasons why internationally accepted reference materials are needed in addition to the primary, scale defining reference materials [7] such as Vienna Standard Mean Ocean Water (VSMOW and VSMOW2) and Standard Light Antarctic Precipitation (SLAP and SLAP2) which scale anchor the ${ }^{2} \mathrm{H}$ as well as the ${ }^{18} \mathrm{O} \delta$ scale $[6,10,17,18]$. For one, for historical reasons the primary scale defining reference materials are inorganic compounds whose chemical elemental composition does not match that of organic compounds and materials. For another, limited stocks of primary reference materials place restrictions on how much and at which intervals they can be supplied to any one laboratory. To overcome these constraints, internationally accepted and distributed secondary reference materials have been made available "to bridge the materials and chemistry gap" [7]. Secondary reference materials are traceable to the scale defining primary reference materials but unlike the defined $\delta$ values of primary reference materials, specified $\delta$ values of secondary reference 
materials are associated with an uncertainty envelope (Table 2). A list of distributors of reference materials is given in Table 3.

However, even secondary reference materials (Table 2) are not available in limitless supply, which means it is not practically feasible to use them directly as Equation 1 implies. They are therefore more efficiently used to scale normalise and thus calibrate "raw" $\delta$ values that have been measured against a working gas. It must be emphasized, measured $\delta$ values calculated by instrument software on the basis of a working gas peak are neither calibrated nor scale normalised even if the isotopic composition of the working gas is known. As illustrated by the example shown in Table 1, scale normalization requires at least two reference materials acting as scale anchors. Furthermore, in continuous-flow IRMS instruments working gas pulses are introduced in a gas stream separate to the sample gas stream and are not subject to the same physical and chemical processes as the samples. For these two reasons the use of working gas pulses does not meet with the Identical Treatment principle $[7,19,20]$.

What does work however while meeting all requirements discussed above is using reference materials and working gases in combination (Figure 2; Table 4). This means both samples and reference materials serving as scale anchors are analysed under identical conditions and their measured $\delta$ values are expressed relative to a working gas. Measured $\delta$ values of reference materials 1 and 2 (RM1 and RM2) are subsequently compared to their accepted $\delta$ values on the relevant isotope reference scale. A linear regression line is fitted through the data points (RM1 $1_{\text {measured }}$, $\left.\mathrm{RM} 1_{\text {accepted }}\right)$ and $\left(\mathrm{RM} 2_{\text {measured, }} \mathrm{RM} 2_{\text {accepted }}\right)$ to yield a scale normalization equation of the form

$$
\begin{gathered}
\qquad \delta^{\mathrm{h}} \mathrm{E}_{\text {scale }}=\mathrm{s} \times \delta^{\mathrm{h}} \mathrm{E}_{\text {measured }}+\mathrm{b} \\
\text { where } \mathrm{s}=\left(\mathrm{RM} 2_{\text {accepted }}-\mathrm{RM} 1_{\text {accepted }}\right) /\left(\mathrm{RM} 2_{\text {measured }}-\mathrm{RM} 1_{\text {measured }}\right) \\
\text { and } \mathrm{b}=\mathrm{RM} 1_{\text {accepted }}-\left(\mathrm{s} \times \mathrm{RM} 1_{\text {measured }}\right)=\mathrm{RM} 2_{\text {accepted }}-\left(\mathrm{s} \times \mathrm{RM} 2_{\text {measured }}\right)
\end{gathered}
$$


Given what has been said thus far, it should be obvious that in principle the $\delta$ value of the working gas does not have to be known and could be set arbitrarily to any value. However, there are practical reasons why it is useful for the approximate $\delta$ value of the working gas to be known. This is easily achieved by measuring pulses of the working gas against a single reference material. The most important practical reason for doing so is for raw $\delta$ values (i.e. based on working gas $\delta$ values) to serve as decision enabling acceptance criteria. More often than not, sample material is in limited supply so a decision as to whether a batch run analysis can proceed or should be aborted has to be made early on, e.g. based on measured $\delta$ values of RM1 and thus before any samples (Table 4). In fact, standard operating procedures for accredited analytical processes require defined acceptance criteria on which basis a decision is made if an analytical batch sequence has to be stopped or is permitted to proceed.

\section{Why and which secondary reference materials are appropriate scale anchors}

As discussed above, in terms of sample turn-around and efficient use of reference materials working gases offer a convenient way to generate raw $\delta$ values indicative of a sample's actual isotope abundance. Cylinder gases, however well their isotopic composition may be known are not equivalent to the scale defining primary reference materials that anchor a particular $\delta^{\mathrm{h}} \mathrm{E}$ value reference scale. Most scale defining primary reference materials are however inorganic compounds or materials that are either not directly amenable or directly comparable to stable isotope analysis of organic compounds and materials by Continuous Flow - IRMS (CF-IRMS). For this reason, numerous secondary (often organic) reference materials have been developed (Table 2). Like primary reference materials secondary reference materials are internationally agreed-upon and are administered and distributed by internationally 
recognised organisations (Table 3). Their scale normalised $\delta$ values are based on statistically valid results submitted by stable isotope laboratories that had participated in international inter-laboratory exercises organised by the IAEA or other organisations. The purpose of internationally distributed reference materials is to anchor $\delta^{\mathrm{h}} \mathrm{E}$ scales and to enable comparable measurement results in stable isotope laboratories no matter their location in the world. The majority of these secondary international reference materials are listed on the website of the International Union of Pure and Applied Chemistry's (IUPAC) Commission on Isotopic Abundances and Atomic Weights (CIAAW) at www.ciaaw.org. The importance of international isotopic reference materials to produce robust, traceable and internationally comparable results has been emphasized by IUPAC guidelines that have been widely published $[6,7,10]$.

- If a secondary international measurement standard defines the size of a $\delta^{\mathrm{h}} \mathrm{E}$ scale, such as SLAP (SLAP2) water for $\delta^{2} \mathrm{H}$ and $\delta^{18} \mathrm{O}$ measurements, $\delta^{\mathrm{h}} \mathrm{E}$ values should be normalised using both standards. The authors should state this clearly in their articles and reports.

- Authors are also encouraged to analyse with their samples and report $\delta^{\mathrm{h}} \mathrm{E}$ values of further internationally distributed reference materials as appropriate for the measurement method concerned. Secondary internationally distributed isotopic reference materials that are of a nature similar to those of the unknowns being measured (sulphate, nitrate, cellulose, etc.) should be analysed. This has been called the Identical Treatment principle [19] and minimises systematic errors by subjecting sample unknowns and reference materials to exactly the same chemical and other manipulation steps, including the transfer pathway to the ion source of the IRMS. In this manner, measurement results can be adjusted in the future as analytical methods 
improve and consensus values of internationally distributed isotopic reference materials are amended.

Therefore it follows from the above preferably any two secondary reference materials whose $\delta^{\mathrm{h}} \mathrm{E}$ values extend closely to the size of the relevant $\delta^{\mathrm{h}} \mathrm{E}$ scale can serve as appropriate scale anchors. Even more preferably, such two secondary reference materials should be a good matrix match with regards to chemical nature and relative elemental composition of the samples. For example reference materials USGS40 and USGS41a are both glutamic acid but of different ${ }^{13} \mathrm{C}$ and different ${ }^{15} \mathrm{~N}$ abundance (Table 2). As amino acid the elemental $\mathrm{C} / \mathrm{N}$ ratio of glutamic acid resembles the $\mathrm{C} / \mathrm{N}$ ratio typically associated with that of peptides and proteins. Similarly, for ${ }^{2} \mathrm{H}$ or ${ }^{13} \mathrm{C}$ analysis of hydrocarbons or long chain fatty acids reference material pairs USGS67 / USGS69 or USGS70 / USGS72 respectively are ideally matched and can thus serve as appropriate scale anchors (Table 2). For bulk ${ }^{2} \mathrm{H}$ analysis of organic compounds, in particular solids by TC/EA-IRMS (Thermal Conversion/Elemental Analyser IRMS) the need for well matched reference materials was a major concern up until recently. Thanks to the efforts by Haiping Qi and Tyler Coplen (USGS Reston, VA, USA) scale anchoring primary reference materials VSMOW and SLAP2 have become available sealed in cold-welded silver tubes. This makes them thus amenable to be loaded on autosamplers for solids and to be analysed side-by-side with solid samples for both bulk ${ }^{2} \mathrm{H}$ and bulk ${ }^{18} \mathrm{O}$ abundance by TC/EA-IRMS [21]. Recognising the resource constraints put on use of VSMOW and SLAP2, secondary reference waters have been developed, also available sealed in silver tubes from USGS Reston, whose $\delta^{2} \mathrm{H}_{\text {VSMOw }}$ and $\delta^{18} \mathrm{O}_{\text {VSMOw }}$ values cover the range of the VSMOW/SLAP scale (Tables 2, 3). 


\section{Why appropriate choice of reference materials is crucial}

The importance of which pair of reference materials are chosen to act as end-points, i.e. scale anchors cannot be stressed enough. The narrower the $\delta$ value range or bracket covered by one's choice of reference materials is, the less accurate the resulting normalisation will be of measured $\delta$ values outside that bracket (Figure 3). In the example shown in Figure 3 the $\delta^{2} \mathrm{H}_{\text {VSMOw }}$ values of reference materials IAEA-CH-7 and IA-R002 bracket merely a $\delta^{2} \mathrm{H}$ value range of $10.9 \%$, i.e. nowhere near the $\delta^{2} \mathrm{H}$ value range of $427.5 \%$ covered by VSMOW / SLAP2. As a consequence, the linear correction equation based on IAEA-CH-7 and IR-R002 is significantly different from the scale normalisation equation obtained from contemporaneously analysed VSMOW and SLAP2 yielding as it does a "calibrated" $\delta^{2} \mathrm{H}$ value of $-198.0 \%$ for GISP that compared to its accepted $\delta^{2} \mathrm{H}_{\text {VSMOw }}$ value of $-189.7 \%$ is $8.3 \%$ too negative.

An analogous impact of too narrow a $\delta^{13} \mathrm{C}$ value range is illustrated by the example shown in Figure 4a. Here the $\delta^{13} \mathrm{C}$ range of 1.38 \% covered by reference materials IAEA-600 and USGS40 chosen as end points has a significant impact on accuracy of "corrected" $\delta^{13} \mathrm{C}$ values. The difference of 0.283 \% may seem small between the "not-toscale-calibrated" $\delta^{13} \mathrm{C}$ value of $-10.733 \%$ for IAEA-CH-6 and its scale normalised $\delta^{13} \mathrm{C}$ value of $-10.45 \%$. However, based on the acceptance criterion for modern IRMS instruments of $0.06 \%$ for repeatability of $\delta^{13} \mathrm{C}$ measurements, the difference of $0.283 \%$ of (accepted minus corrected) is 4.72 times higher than this and thus statistically significant.

Considering how close proximity of two end-points results in pronounced differences for slope and off-set between the corresponding linear regression equation and that obtained from using appropriate scale anchors, one can understand why socalled single point calibrations cannot be and are not fit for purpose (Figure 4b). Obviously, a single point is not sufficient to define a linear equation given the slope $\mathrm{s}$ of a line is given by the ratio of 
$(y 2-y 1) /(x 2-x 1)$. A so-called single point "calibration" does most certainly not meet the aforementioned IUPAC requirement of normalising measured $\delta$ values to the size of the relevant $\delta$ scale. Furthermore, by using merely one reference material as a single point of comparison to correct measured $\delta$ values one either assumes a slope equal to $1(\mathrm{y}=\mathrm{x}+\mathrm{b})$ or an off-set of zero $(y=a \times x)$. In case of the former the off-set "b" would be determined by ( $\left.\mathrm{RM}_{\text {accepted }}-\mathrm{RM}_{\text {measured }}\right)$. In case of the latter the correction factor "a" would be determined by $\left(\mathrm{RM}_{\text {accepted }} / \mathrm{RM}_{\text {measured}}\right)$. However, either approach does not yield accurate, let alone scale normalised $\delta$ values as Figure $4 \mathrm{~b}$ illustrates for the scenario $\mathrm{y}=\mathrm{x}+\mathrm{b}$. While the difference of $0.16 \%$ between single-point corrected and scale normalised $\delta^{13} \mathrm{C}$ value of IAEA-CH-6 seems small, it is still 2.67 times higher than the acceptance criterion of $0.06 \%$ for repeatability of $\delta^{13} \mathrm{C}$ measurements.

The examples discussed above illustrate quite clearly the importance of ensuring the two reference materials chosen as scale anchors are indeed end-points whose $\delta$ values extend to if not match the size of the relevant $\delta$ scale. Furthermore, in addition to meeting with this condition one should also take care when selecting reference materials with regards to their physical properties and chemical elemental composition.

Modern on-line interfaces perform chemical conversion into a mixture of simple gases and subsequent chromatographic separation of this gas mixture into individual gas peaks. The combination of these different on-line processes in conjunction with transporting permanent gases of low molecular weight in a carrier gas stream may be subject to potential mass discriminatory effects. Further factors affecting measurement accuracy of $\delta$ values are memory effects but also peak detection and peak integration by proprietary instrument software. Adherence to the Identical Treatment principle of sample and standard can minimise any analytical bias only when samples and reference materials are of comparable chemical and elemental compositions, which is termed matrix matching. 
For example, stable isotope analysis of ammonia salts or nitrogen bearing organic compounds for their ${ }^{15} \mathrm{~N}$ abundance is one example where appropriate choice of reference materials in terms of matrix matching is extremely important. In ammonium salts or organic amines or amides, nitrogen is present in states of oxidation ranging from -IV to -I. However, reference materials USGS32 and USGS34 are both nitrates where nitrogen is present in its highest state of oxidation, namely $+\mathrm{V}$. While in ammonium salts and nitrogen bearing organic compounds nitrogen will be oxidised to states of oxidation of 0 $\left(\mathrm{N}_{2}\right)$ or possibly $+\mathrm{II}(\mathrm{NO})$, nitrogen in nitrates cannot be oxidised any further but has to be reduced to +IV $\left(\mathrm{NO}_{2}\right)$ or + II (NO). Therefore, organic reference materials such as Lvaline or caffeine should be chosen as scale anchors to ensure Identical Treatment during compound conversion of nitrogen bearing organic compounds such as amino acids or hetero-aromatic compounds respectively (Table 2).

Conversely, when analysing nitrate samples for their ${ }^{15} \mathrm{~N}$ abundance, it is equally important to use nitrate reference materials as scale anchors. This is not only important from a matrix matching point of view but also from a sample conversion point of view. The conversion of nitrates into ultimately $\mathrm{N}_{2}$ gas relies on thermolysis of $\left[\mathrm{NO}_{3}\right]^{-}$into $\mathrm{NO}, \mathrm{NO}_{2}$ and $\mathrm{O}_{2}$, i.e. a reaction that generates oxygen rather than combustion, which consumes and thus requires oxygen. This means conversion of nitrates in an EA has to be carried out without the otherwise customary pulse of oxygen [22].

Last but not least attention is drawn to the perhaps confusing situation concerning scale normalisation of $\delta^{18} \mathrm{O}$ values. For historic reasons, there are three $\delta$ scales in use; $\delta^{18} \mathrm{O}_{\text {VSMOW, }} \delta^{18} \mathrm{O}_{\text {VPDB }}$ and $\delta^{18} \mathrm{O}_{\text {Air-O2. }}$. While reports of $\delta^{18} \mathrm{O}_{\text {Air-O2 }}$ values are few and far between, reporting $\delta^{18} \mathrm{O}$ values of carbonates as $\delta^{18} \mathrm{O}_{\text {VPDB }}$ values is still quite common even though CIAAW's list of ${ }^{18} \mathrm{O}$ reference materials now states $\delta^{18} \mathrm{O}_{\text {VSMOw }}$ values throughout, including carbonate reference materials. It is crucially important to stay with one $\delta^{18} \mathrm{O}$ 
reference scale when reporting and dealing with $\delta^{18} \mathrm{O}$ values, and especially, when performing calculations involving $\delta^{18} \mathrm{O}$ values. This may seem obvious, however, a glance at published articles reveals it is not $[23,24]$. Subtracting $\delta^{18} \mathrm{O}_{\text {VSMOw }}$ values from $\delta^{18} \mathrm{O}_{\text {VPDB }}$ values makes about as much sense as subtracting $\mathrm{kJ}$ from kcal or ounces from grams. For meaningful scale normalisation of measured $\delta^{18} \mathrm{O}$ values to either the VSMOW or the VPDB scale, accepted $\delta^{18} \mathrm{O}$ values of the two reference materials chosen as scale anchors must be expressed on the same reference scale. Should instrumental or experimental set-up make it necessary for measurement results of two different sets of samples to be expressed on either of the two reference scales, this should be clearly stated in reports and publications. Furthermore, prior to any calculation involving both data sets $\delta^{18} \mathrm{O}_{\mathrm{vSMOw}}$ values have to be converted into $\delta^{18} \mathrm{O}_{\mathrm{VPDB}}$ values or vice versa. The conversion equations originally given by Friedman and O'Neil [25] were:

$$
\begin{aligned}
& \delta^{18} \mathrm{O}_{\text {VSMOW }}=1.03086 \times \delta^{18} \mathrm{O}_{\text {VPDB }}+30.86 \\
& \delta^{18} \mathrm{O}_{\text {VPDB }}=0.97006 \times \delta^{18} \mathrm{O}_{\text {VSMOW }}-29.94
\end{aligned}
$$

Please, note in equations (3) and (4) scale reference points SMOW and PDB in [25] have been amended to read VSMOW and VPDB in line with latest IUPAC guidelines [10].

However, with continuously advancing technology, new studies and resulting new insights, relations such as expressed in equations (3) and (4) are continuously being refined. Readers are therefore advised to visit e.g. the CIAAW website to check for the latest information [26]. With regards to the relation between $\delta^{18} \mathrm{O}_{\text {VSMOw }}$ and $\delta^{18} \mathrm{O}_{\mathrm{VPDB}}$ values the CIAAW web page for oxygen reference materials currently states this equation $[7,27]$ :

$$
\delta^{18} \mathrm{O}_{\mathrm{VPDB}}=0.97001 \times \delta^{18} \mathrm{O}_{\mathrm{VSMOW}}-29.99
$$




\section{Conclusions}

- Most published methods sections describing stable isotopic analytical approaches and resulting $\delta$ values reflect shortcomings or even blatant misconceptions with regard to the proper use of reference materials, calibration, isotopic scale normalisation, and adherence to SI-rules and recommended IUPAC isotopic nomenclature.

- This paper offers detailed guidance about the mandatory use of isotopic reference materials for 2 end-point scale normalisation and calibrations against common isotopic scales.

- Practical examples of small data sets with various underlying scale normalisation and calibration strategies demonstrate the severity of isotopic artefacts resulting from inappropriately chosen "end"-points, inadmissible single-point calibration and violations of the principle of Identical Treatment of sample and standard.

- We offer a list of prominent suppliers of light stable isotope reference materials to best match sample matrices encountered by stable isotope practitioners with chemically similar reference materials to adhere to the Identical Treatment principle of sample and standard (Table 3).

- Proper use of reference materials and reporting of $\delta$ values fosters interdisciplinary communication while minimising ambiguity and reducing the jargon of scientific subdisciplines. 


\section{References}

[1] de Groot PA, editor. Handbook of Stable Isotope Analytical Techniques. Amsterdam: Elsevier B.V.; 2004.

[2] Fry B. Stable Isotope Ecology. New York (NY 10013): Springer; 2006. https://doi.org/10.1007/0-387-33745-8; http://www.jlakes.org/ch/web/0-387-337458.pdf

[3] Carter JF, Chesson LA, editors. Food Forensics: Stable Isotopes as a Guide to Authenticity and Origin. Boca Raton (FL): CRC Press, Taylor \& Francis Group; 2017.

[4] Sharp Z. Principles of Stable Isotope Geochemistry, 2nd Edition. University of New Mexico, Albuquerque (NM); 2017. http://digitalrepository.unm.edu/unm_oer/1/

[5] Meier-Augenstein W. Stable Isotope Forensics - 2nd Edition: Methods and Forensic Applications of Stable Isotope Analysis. Chichester (UK): John Wiley \& Sons Ltd; 2018.

[6] Brand WA, Coplen TB. Stable isotope deltas: tiny, yet robust signatures in nature. Isotopes Environ Health Stud. 2012; 48: 393-409. https://doi.org/10.1080/10256016.2012.666977

[7] Brand WA, Coplen TB, Vogl J, et al. Assessment of international reference materials for isotope-ratio analysis (IUPAC Technical Report). Pure Appl Chem. 2014; 86: 425-467. https://doi.org/10.1515/pac-2013-1023

[8] Coleman M, Meier-Augenstein W. Ignoring IUPAC guidelines for measurement and reporting of stable isotope abundance values affects us all. Rapid Commun Mass Spectrom. 2014; 28: 1953-1955. https://doi.org/10.1002/rcm.6971

[9] Brand WA, Assonov SS, Coplen TB. Correction for the ${ }^{17} \mathrm{O}$ interference in $\delta\left({ }^{13} \mathrm{C}\right)$ measurements when analyzing $\mathrm{CO}_{2}$ with stable isotope mass spectrometry (IUPAC Technical Report). Pure Appl Chem. 2010; 82: 1719-1733. https://doi.org/10.1351/PAC-REP-09-01-05

[10] Coplen TB. Guidelines and recommended terms for expression of stable-isotoperatio and gas-ratio measurement results. Rapid Commun Mass Spectrom. 2011; 25: 2538-2560. https://doi.org/10.1002/rcm.5129

[11] Park R, Epstein S. Metabolic fractionation of $C^{13} \& C^{12}$ in plants. Plant Physiol. 1961; 36: 133-138. https://doi.org/10.1104/pp.36.2.133 
[12] Park R, Epstein S. Carbon isotope fractionation during photosynthesis. Geochim Cosmochim Acta. 1960; 21: 110-126. https://doi.org/10.1016/S00167037(60)80006-3

[13] Bender MM. Variations in the ${ }^{13} \mathrm{C} /{ }^{12} \mathrm{C}$ ratios of plants in relation to the pathway of photosynthetic carbon dioxide fixation. Phytochem. 1971; 10: 1239-1244. https://doi.org/10.1016/S0031-9422(00)84324-1

[14] Coplen TB. Normalization of oxygen and hydrogen isotope data. Chem Geol. 1988; 72: 293-297. https://doi.org/10.1016/0168-9622(88)90042-5

[15] Horita J, Kendall C. Stable isotope analysis of water and aqueous solutions by conventional dual-inlet mass spectrometry. In: de Groot PA, editor. Handbook of Stable Isotope Analytical Techniques, Volume I, Chapter 1. Amsterdam (Netherlands): Elsevier B.V.; 2004; pp. 1-37. https://doi.org/10.1016/ $\underline{\text { B978-044451114-0/50003-X }}$

[16] Schimmelmann A, Qi H, Coplen TB, et al. New organic reference materials for hydrogen, carbon, and nitrogen stable isotope-ratio measurements: caffeines, $n$-alkanes, fatty acid methyl esters, glycines, L-valines, polyethylenes, and oils. Anal Chem. 2016; 88: 4294-4302. https://doi.org/10.1021/acs.analchem.5b04392

[17] Coplen TB. New guidelines for reporting stable hydrogen, carbon, and oxygen isotoperatio data. Geochim Cosmochim Acta. 1996; 60: 3359-3360. https://doi.org/10.1016/0016-7037(96)00263-3

[18] Coplen TB, Brand WA, Gehre M, et al. New guidelines for $\delta^{13} \mathrm{C}$ measurements. Anal Chem. 2006; 78: 2439-2441. https://doi.org/10.1021/ac052027c

[19] Werner RA, Brand WA. Referencing strategies and techniques in stable isotope ratio analysis. Rapid Commun Mass Spectrom. 2001; 15: 501-519. https://doi.org/10.1002/rcm.258

[20] Renpenning J, Kümmel S, Hitzfeld KL, et al. Compound-specific hydrogen isotope analysis of heteroatom-bearing compounds via gas chromatography -chromium-based High-Temperature Conversion (Cr/HTC) - Isotope Ratio Mass Spectrometry. Anal Chem. 2015; 87: 9443-9450. https://doi.org/10.1021/acs.analchem.5b02475

[21] Qi H, Gröning M, Coplen TB, et al. Novel silver-tubing method for quantitative introduction of water into high-temperature conversion systems for stable hydrogen and oxygen isotopic measurements. Rapid Commun Mass Spectrom. 2010; 24: 1821-1827. https://doi.org/10.1002/rcm.4559 
[22] Gentile N, Rossi MJ, Delémont O, et al. $\delta^{15} \mathrm{~N}$ measurement of organic and inorganic substances by EA-IRMS: a speciation-dependent procedure. Anal Bioanal Chem. 2013; 405: 159-176. https://doi.org/10.1007/s00216-012-6471-z

[23] Dorval E, Piner K, Robertson L et al. Temperature record in the oxygen stable isotopes of Pacific sardine otoliths: Experimental vs. wild stocks from the Southern California Bight. J Exp Mar Biol Ecol. 2011; 397; 136-143.

https://doi.org/10.1016/j.jembe.2010.11.024

[24] Sakamoto T, Komatsu K, Yoneda M et al. Temperature dependence of $\delta^{18} \mathrm{O}$ in otolith of juvenile Japanese sardine: Laboratory rearing experiment with microscale analysis. Fish Res. 2017; 194; 55-59. https://doi.org/10.1016/j.fishres.2017.05.004

[25] Friedman I, O'Neil JR. Compilation of stable isotope fractionation factors of geochemical interest. In: Data of Geochemistry, Sixth Edition. Geological Survey Professional Paper 440-KK. Washington (DC): U.S. Government Printing Office; 1977; pp. KK1-KK12. https://pubs.usgs.gov/pp/0440kk/report.pdf

[26] http://ciaaw.org/oxygen-references.htm

[27] Kim S-T, Coplen TB, Horita J. Normalization of stable iotope data for carbonate minerals: Implementation of IUPAC guidelines. Geochim Cosmochim Acta. 2015; 158; 276-289. https://doi.org/10.1016/j.gca.2015.02.011 
Table 1. Difference between measured $\delta^{2} \mathrm{H}$ values and $\delta^{2} \mathrm{H}_{\text {Vsmow values calibrated by two }}$ end-point scale normalization.

Table 2: Select list of reference materials that can serve as scale anchors (SCAN). Some reference materials listed include a matching quality control (QC). ${ }^{\text {a) }}$

Table 3. Distributors of light stable isotope reference materials (RMs) in alphabetical order.

Table 4. Generic batch sequence run sheet favouring high sample throughput under stable experimental conditions using ${ }^{13} \mathrm{C}$ abundance analysis as example.

Figure 1. Comparison of variability and thus precision of quantitative mass spectrometric analysis based (a) on absolute $\mathrm{m} / \mathrm{z}$ abundance measurement and (b) on $\mathrm{m} / \mathrm{z}$ abundance ratio determination.

Figure 2. Flowchart for isotope abundance analysis observing the Identical Treatment principle for both samples and reference materials serving as scale anchors.

Figure 3. Impact of reference material choice as end-points for $\delta^{2} \mathrm{H}$ scale normalization on correction equation and corrected $\delta^{2} \mathrm{H}$ values.

Figure 4. Comparison of impact of reference material choice (a) as end-points or (b) as single-point for $\delta^{13} \mathrm{C}$ scale normalization on correction equation and corrected $\delta^{13} \mathrm{C}$ values. 
Tables for RM manuscript

Table 1: Difference between measured $\delta^{2} \mathrm{H}$ values and $\delta^{2} \mathrm{H}_{\text {Vsmow values calibrated by two }}$ end-point scale normalization.

\begin{tabular}{|l|c|c|c|}
\hline Compound Name & $10^{3} \times \delta^{2} \mathrm{H}_{\text {measured }}$ & $10^{3} \times \delta^{2} \mathrm{H}_{\text {VSMOW }}$ & $10^{3} \times \Delta \delta^{2} \mathrm{H}$ \\
\hline VSMOW2 & -0.36 & 0.00 & 0.36 \\
\hline NBS 22; $10^{3} \times \delta^{2} \mathrm{H}_{\text {accepted }}=-117.2$ & -108.54 & -117.00 & 8.46 \\
\hline SLAP2 & -395.68 & -427.50 & 31.82 \\
\hline
\end{tabular}


Table 2: Select list of reference materials that can serve as scale anchors (SCAN). Some reference materials listed include a matching quality control (QC). ${ }^{\text {a) }}$

\begin{tabular}{|c|c|c|c|c|}
\hline $\begin{array}{l}\text { Reference } \\
\text { Material ID }\end{array}$ & Compound Name & $10^{3} \times \delta^{2} \mathrm{H}_{\mathrm{VSMOW}}$ & $10^{3} \times \delta^{13} \mathrm{C}_{\mathrm{VPDB}}$ & $10^{3} \times \delta^{15} \mathrm{~N}_{\text {Air }}$ \\
\hline VSMOW2 & Water (SCAN \#1) & 0.0 & & \\
\hline GISP2 & Water (QCl) & -258.3 & & \\
\hline SLAP2 & Water (SCAN \#2) & -427.5 & & \\
\hline USGS48 & Water (SCAN \#1) & $-2.0 \pm 0.4$ & & \\
\hline USGS47 & Water (QCl) & $-150.2 \pm 0.5$ & & \\
\hline USGS49 & Water (SCAN \#2) & $-394.7 \pm 0.4$ & & \\
\hline USGS40 & L-glutamic acid (SCAN \#1) & & $-26.39 \pm 0.04$ & $-4.52 \pm 0.06$ \\
\hline USGS41a & L-glutamic acid (SCAN \#2) & & $+36.55 \pm 0.08$ & $+47.55 \pm 0.15$ \\
\hline USGS64 & Glycine (SCAN \#1) & & $-40.81 \pm 0.04$ & $+1.76 \pm 0.06$ \\
\hline USGS65 & Glycine (QC) & & $-20.29 \pm 0.04$ & $+20.68 \pm 0.06$ \\
\hline USGS66 & Glycine (SCAN \#2) & & $-0.67 \pm 0.04$ & $+40.83 \pm 0.06$ \\
\hline USGS67 & Hexadecane (SCAN \#1) & $-166.2 \pm 1.0$ & $-34.50 \pm 0.05$ & \\
\hline USGS68 & Hexadecane (QC) & $-10.2 \pm 0.9$ & $-10.55 \pm 0.04$ & \\
\hline USGS69 & Hexadecane (SCAN \#3) & $+381.4 \pm 3.5$ & $-0.57 \pm 0.04$ & \\
\hline USGS70 & $\begin{array}{l}\text { Icosanoic acid methyl ester } \\
(\mathrm{C} 20: 0 \mathrm{FAME})(\mathrm{SCAN} \# 1)\end{array}$ & $-183.9 \pm 1.4$ & $-30.53 \pm 0.04$ & \\
\hline USGS71 & $\begin{array}{l}\text { Icosanoic acid methyl ester } \\
\text { (C20:0 FAME) (QC) }\end{array}$ & $-4.9 \pm 1.0$ & $-10.50 \pm 0.03$ & \\
\hline USGS72 & $\begin{array}{l}\text { Icosanoic acid methyl ester } \\
(\mathrm{C} 20: 0 \mathrm{FAME})(\mathrm{SCAN} \# 2)\end{array}$ & $+348.3 \pm 1.5$ & $-1.54 \pm 0.03$ & \\
\hline $\begin{array}{l}\text { Reference } \\
\text { Material ID }\end{array}$ & Compound Name & & $10^{3} \times \delta^{15} \mathrm{~N}_{\mathrm{Air}}$ & $10^{3} \times \delta^{18} \mathrm{O}_{\text {VSMOW }}$ \\
\hline IAEA-601 & Benzoic acid (SCAN \#1) & & & $+23.14 \pm 0.19$ \\
\hline IAEA-602 & Benzoic acid (SCAN \#2) & & & $+71.28 \pm 0.36$ \\
\hline
\end{tabular}


USGS34 $\mathrm{KNO}_{3}\left({ }^{15} \mathrm{~N}\right.$ or ${ }^{18} \mathrm{O}$ SCAN \#1)

$-1.8 \pm 0.1 \quad-27.78 \pm 0.37$

USGS32 $\mathrm{KNO}_{3}$

$\left({ }^{15} \mathrm{~N}\right.$ SCAN \#2; ${ }^{18} \mathrm{O}$ QC)

$+180.0 \quad+25.4 \pm 0.2$

IAEA-NO-3 $\quad \mathrm{KNO}_{3}\left({ }^{18} \mathrm{O} \mathrm{QC}\right)$

$+25.32 \pm 0.29$

10

11

12

13

14

15

16

17

18

a) Reference material IDs and their $\delta$ values taken from: http://www.ciaaw.org/reference-materials.htm 
Table 3: Distributors of light stable isotope reference materials (RMs) in alphabetical order.

\begin{tabular}{|c|c|c|c|}
\hline Distributor & Web portal or contact & Comments & RM categories \\
\hline $\begin{array}{l}\text { AirLiquide } \\
\quad \text { (international) }\end{array}$ & $\begin{array}{l}\text { http://isotope.airliquide- } \\
\text { expertisecenter.com/ }\end{array}$ & $\begin{array}{l}\text { Gases like } \mathrm{CO}_{2} \text { and } \mathrm{SO}_{2} \\
\text { from cylinders can only } \\
\text { serve as monitoring gases } \\
\text { in on-line applications }\end{array}$ & $\begin{array}{l}\text { Air, trace gases in } \\
\text { air, } \mathrm{CO}, \mathrm{CO}_{2} \\
\mathrm{SO}_{2}, \mathrm{NO}_{\mathrm{x}}, \mathrm{SF}_{6} \\
\text { hydrocarbons }\end{array}$ \\
\hline ANSTO (Australia) & $\begin{array}{l}\text { http://www.ansto.gov.au/Res } \\
\text { earchHub/Ourlnfrastructure/A } \\
\text { CNS/CurrentResearch/Scient } \\
\text { ificHighlights/NDF- } \\
\text { PE77/index.htm ; } \\
\text { tde@ansto.gov.au }\end{array}$ & $\begin{array}{l}\text { NDF-PE77 is isotopically } \\
\text { indistinguishable from } \\
\text { USGS77 powder }\end{array}$ & $\begin{array}{l}\text { Polyethylene line } \\
\text { NDF-PE77 }\end{array}$ \\
\hline $\begin{array}{l}\text { Elemental } \\
\quad \text { Microanalysis } \\
\text { (United Kingdom) }\end{array}$ & $\begin{array}{l}\text { http://www.elementalmicroan } \\
\text { alysis.com/product list.php?t } \\
\text { op=IRMS\%20supplement\&ca } \\
\underline{\text { tegory }=204 \& \text { sub=Certified }}\end{array}$ & $\begin{array}{l}\text { Website offers insufficient } \\
\text { documentation of isotopic } \\
\text { characterization (July 2018) }\end{array}$ & $\begin{array}{l}2 \text { waters, } 3 \\
\text { organic RMs }\end{array}$ \\
\hline $\begin{array}{l}\text { ERM }^{\circledR} \text {, European } \\
\text { Reference } \\
\text { Materials } \\
\text { (Belgium) }\end{array}$ & $\begin{array}{l}\text { https://crm.jrc.ec.europa.eu/c/ } \\
\text { By-application-field/Stable- } \\
\text { isotopes/40476/ }\end{array}$ & $\begin{array}{l}\mathrm{ERM}^{\circledR} \text { and IRMM RMs are } \\
\text { identical and available from } \\
\text { various vendors }\end{array}$ & Inorganic RMs \\
\hline $\begin{array}{l}\text { IAEA, International } \\
\text { Atomic Energy } \\
\text { Agency (Austria) }\end{array}$ & $\begin{array}{l}\frac{\text { https://nucleus.iaea.org/rpst/r }}{\text { eferenceproducts/referencem }} \\
\underline{\text { aterials/Stable Isotopes/inde }} \\
\underline{\text { x.htm }}\end{array}$ & $\begin{array}{l}\text { Isotope data and inventory } \\
\text { not up-to-date on website } \\
\text { as of July } 2018\end{array}$ & $\begin{array}{l}\text { Predominantly } \\
\text { inorganic RMs, } \\
\text { many waters }\end{array}$ \\
\hline $\begin{array}{l}\text { Indiana University, } \\
\text { Department of } \\
\text { Earth and } \\
\text { Atmospheric } \\
\text { Sciences (USA) }\end{array}$ & $\begin{array}{l}\text { https://arndt.schimmelmann.u } \\
\underline{\text { s/welcome.html }}\end{array}$ & 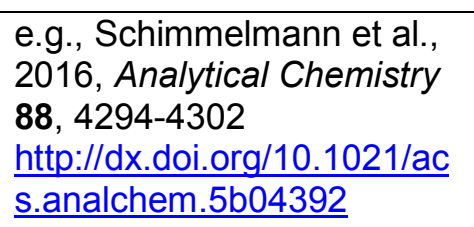 & $\begin{array}{l}\text { Organic RMs } \\
\text { (gases, liquids, } \\
\text { solids, GC-IRMS } \\
\text { mixtures) }\end{array}$ \\
\hline $\begin{array}{l}\text { IRMM, Institute for } \\
\text { Reference } \\
\text { Materials and } \\
\text { Measurements } \\
\text { (Belgium) }\end{array}$ & $\begin{array}{l}\text { https://crm.jrc.ec.europa.eu/c/ } \\
\text { By-application-field/Stable- } \\
\text { isotopes/40476/ }\end{array}$ & $\begin{array}{l}\text { RMs from } \mathrm{ERM}^{\circledR} \text { and IRMM } \\
\text { are identical and available } \\
\text { from various vendors }\end{array}$ & Inorganic RMs \\
\hline $\begin{array}{l}\text { Isometric } \\
\text { Instruments } \\
\text { (Canada) }\end{array}$ & $\begin{array}{l}\text { http://www.isometricinstrume } \\
\text { nts.com/gasstandards.html }\end{array}$ & $\begin{array}{l}\text { Website offers insufficient } \\
\text { documentation of isotopic } \\
\text { characterization (July 2018) }\end{array}$ & Methane in air \\
\hline $\begin{array}{l}\text { NIST, National } \\
\text { Institute of } \\
\text { Standards and } \\
\text { Technology (USA) }\end{array}$ & $\begin{array}{l}\text { https://www- } \\
\text { s.nist.gov/srmors/detail.cfm?s } \\
\text { earchstring=isotope }\end{array}$ & $\begin{array}{l}\text { Isotope data and inventory } \\
\text { not up-to-date on website } \\
\text { as of July } 2018\end{array}$ & $\begin{array}{l}\text { Predominantly } \\
\text { inorganic RMs }\end{array}$ \\
\hline $\begin{array}{l}\text { NMI, National } \\
\text { Measurement } \\
\text { Institute (Australia) }\end{array}$ & $\begin{array}{l}\text { chemref@measurement.gov. } \\
\text { au; available only for WADA- } \\
\text { accredited forensic } \\
\text { laboratories }\end{array}$ & $\begin{array}{l}\text { Tobias and Brenna, 2018, } \\
\text { Drug Testing and Analysis } \\
10(4), 781-785 \\
\underline{\text { https://doi.org/10.1002/dta.2 }} \\
\underline{309}\end{array}$ & $\begin{array}{l}\text { Steroids for } \\
\text { carbon stable } \\
\text { isotope ratios } \\
\text { only }\end{array}$ \\
\hline
\end{tabular}




\begin{tabular}{|c|c|c|c|}
\hline OZTECH (USA) & $\begin{array}{l}\text { isotopems@gmail.com } \\
\text { http://www.si- } \\
\text { science.co.jp/product/data/oz } \\
\text { tech.pdf }\end{array}$ & $\begin{array}{l}\text { Website offers insufficient } \\
\text { documentation of isotopic } \\
\text { characterization (July 2018) }\end{array}$ & $\begin{array}{l}\text { Pure gases } \mathrm{CO}_{2} \\
\mathrm{~N}_{2}, \mathrm{H}_{2}\end{array}$ \\
\hline $\begin{array}{l}\text { Sercon Limited, } \\
\text { Crewe (UK) }\end{array}$ & $\begin{array}{l}\text { https://serconlimited.com/ser } \\
\text { con systems/standards/ }\end{array}$ & $\begin{array}{l}\text { Website offers insufficient } \\
\text { documentation of isotopic } \\
\text { characterization on RMs } \\
\text { proprietary to Sercon (i.e. } \\
\text { RMs with the prefix SC) } \\
\text { (July 2018) }\end{array}$ & $\begin{array}{l}\text { Inorganic and } \\
\text { organic RMs; } \\
\text { waters; flours and } \\
\text { soils }\end{array}$ \\
\hline $\begin{array}{l}\text { SHOKO Science } \\
\text { (Japan) }\end{array}$ & $\begin{array}{l}\text { https://www.si- } \\
\text { science.co.jp/global/en/index. } \\
\underline{\text { html }}\end{array}$ & $\begin{array}{l}\text { RMs partially co-developed } \\
\text { with JAMSTEC and Indiana } \\
\text { University }\end{array}$ & $\begin{array}{l}\text { Amino acids and } \\
\text { waters }\end{array}$ \\
\hline $\begin{array}{l}\text { USGS, United } \\
\text { States Geological } \\
\text { Survey, Reston, } \\
\text { Virginia (USA) }\end{array}$ & $\frac{\text { https://isotopes.usgs.gov/lab/ }}{\text { referencematerials.html }}$ & $\begin{array}{l}\text { Up-to-date isotope data on } \\
\text { website; waters available in } \\
\text { crimp-sealed silver capillary } \\
\text { segments }\end{array}$ & $\begin{array}{l}\text { Inorganic and } \\
\text { organic RMs, } \\
\text { including collagen } \\
\text { and keratin }\end{array}$ \\
\hline $\begin{array}{l}\text { USGS, United } \\
\text { States Geological } \\
\text { Survey, Denver, } \\
\text { Colorado (USA) }\end{array}$ & $\begin{array}{l}\frac{\text { https://energy.usgs.gov/Geoc }}{\text { hemistryGeophysics/Geoche }} \\
\text { mistryLaboratories/GasStand } \\
\text { ards.aspx }\end{array}$ & $\begin{array}{l}\text { Dai et al., 2012, Chemical } \\
\text { Geology 310-311, 49-55. } \\
\text { https://doi.org/10.1016/i.che } \\
\text { mgeo.2012.03.008 }\end{array}$ & $\begin{array}{l}\text { Natural gas RMs } \\
\text { of different } \\
\text { geological origins }\end{array}$ \\
\hline
\end{tabular}


Table 4: Generic batch sequence run sheet favouring high sample throughput under stable experimental conditions using ${ }^{13} \mathrm{C}$ abundance analysis as example.

\begin{tabular}{c|c|c|c|c}
\multirow{2}{*}{ Sample ID } & \multicolumn{2}{|c|}{$\mathbf{1 0}^{\mathbf{3}} \times \boldsymbol{\delta}^{\mathbf{1 3}} \mathbf{C}$} & $\mathbf{1 0}^{\mathbf{3}} \times \boldsymbol{\delta}^{\mathbf{1 3}} \mathbf{C}_{\text {VPDB }}$ \\
& Measured & Corrected & Mean \pm S.D. & Accepted \\
\hline BLANK & & & & \\
\hline RM1 (USGS40) & & & & -26.39 \\
\hline RM1 (USGS40) & & & & -26.39 \\
\hline RM1 (USGS40) & & & & -26.39 \\
\hline RM1 (USGS40) & & & & -26.39 \\
\hline
\end{tabular}

\section{Samples $k$ to $l$}

\begin{tabular}{c|l|l|l|l}
\hline AQC (IAEA-CH-6) & & & & -10.45 \\
\hline AQC (IAEA-CH-6) & & & & -10.45 \\
\hline AQC (IAEA-CH-6) & & & & -10.45 \\
\hline AQC (IAEA-CH-6) & & & & -10.45 \\
\hline
\end{tabular}

Samples $m$ to $n$

\begin{tabular}{c|l|l|l|l}
\hline RM2 (USGS41a) & & & & +36.55 \\
\hline RM2 (USGS41a) & & & & +36.55 \\
\hline RM2 (USGS41a) & & & & +36.55 \\
\hline RM2 (USGS41a) & & & & +36.55 \\
\hline BLANK & & & &
\end{tabular}

a) $\mathrm{RM}=$ International Reference Material/s (here USGS40 and USGS41a) used to scale anchor measured $\delta^{13} \mathrm{C}$ values on the VPDB scale. AQC $=$ acquisition quality control sample/s (here IAEA-CH-6) used to control quality of scale normalisation. 
Planning of analyses
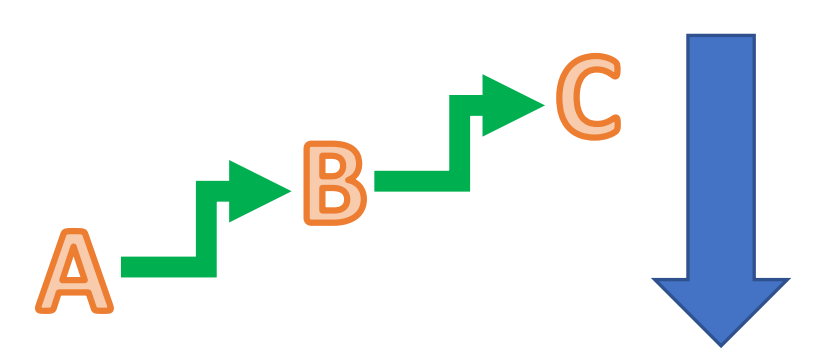

Performing analyses

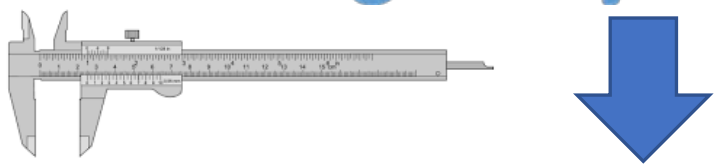

Scale normalisation
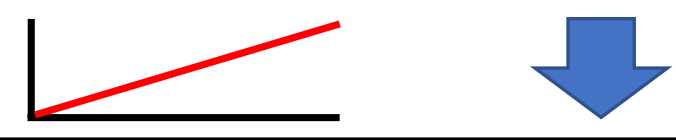

Reporting of data

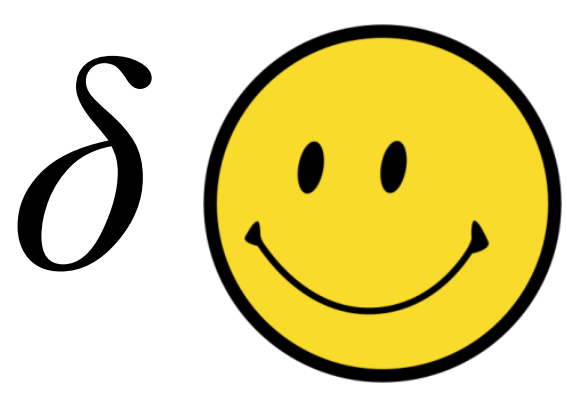

Obtain $\geq 2$ suitable international primary or secondary isotope reference materials (RMs) for your analytical application that should bracket the $\delta$-values that you expect from your unknown samples. The $\delta$-value bracket size should match the size of the $\delta$-scale.

Optional: At a time when your stable isotope ratio analytical instruments work well, calibrate your own tertiary laboratory RMs against international RMs. The chosen RMs should bracket the $\delta$-values that you expect from your unknown samples.

Measure the $\geq 2$ RMs and your unknown samples in a single analytical session in identical fashion, thus adhering to the principle of Identical Treatment (IT) of standard and sample. The resulting $\delta$-values are raw, uncalibrated data.

Use proper statistical methods to linearly scale-normalise raw $\delta$-values towards matching of $\delta$-values of RMs with their prescribed $\delta$-values.

When describing analytical methods, explain which primary, secondary or tertiary RMs were used and which $\delta$-values were assigned to each RM.

Propagate the errors of scale-normalised $\delta$-values based on the empirically determined precision of repeat analyses and the accuracy of RM $\delta$-values.

Use SI-mandated and IUPAC-recommended nomenclature when naming isotopes and expressing $\delta$-values in terms of permil (\%o) or milliurey (mUr). 


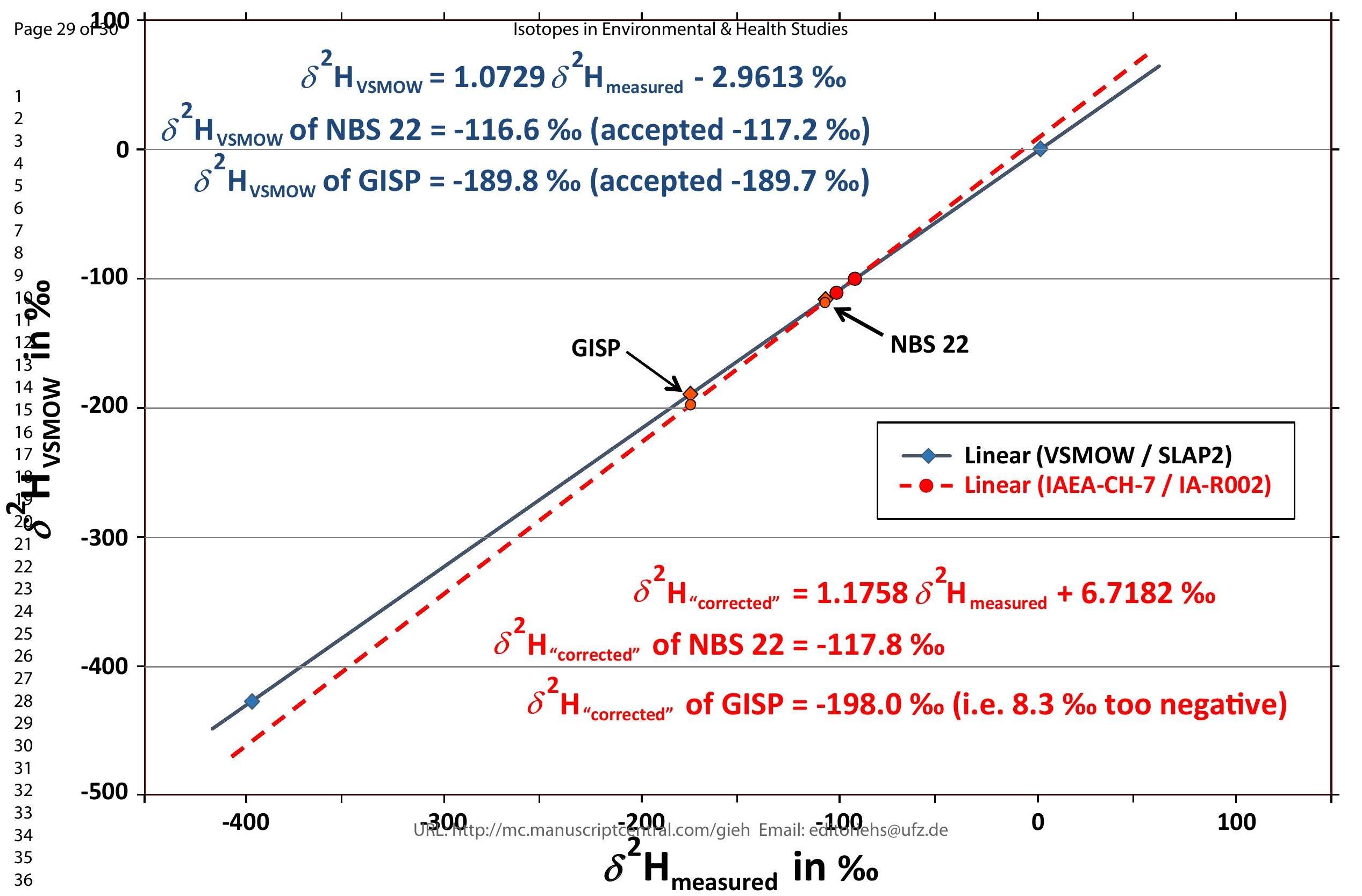




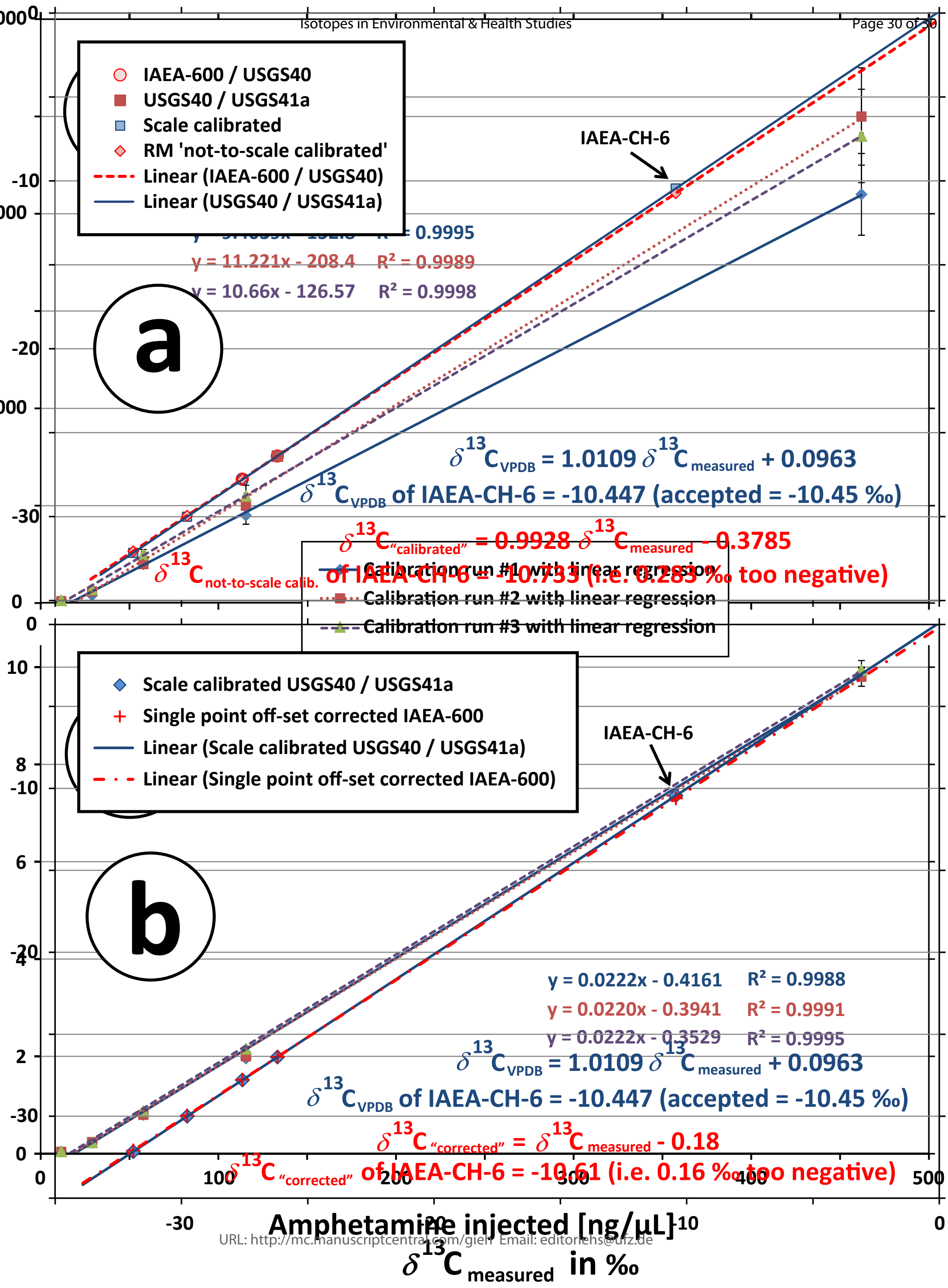

